\title{
ANÁLISIS Y PERSPECTIVAS DE LA INFORMACIÓN RELIGIOSA ESPECIALIZADA
}

\author{
Fernando Cordero Morales \\ (Universidad de Sevilla) \\ anda.tierra@planalfa.es
}

Resumen:

El hecho religioso, tan connatural a la vida humana, sigue interesando en la sociedad actual y, por tanto, también a los medios de comunicación. Nos aproximamos a la compleja y pluriforme realidad de la información religiosa en España, haciendo hincapié en la especialización de los profesionales y también atisbando nuevas vías que se ofrecen a este tipo de mensajes en el panorama mediático. Detectamos algunas cuestiones que ponen en tensión la práctica periodística y el mensaje eclesial, poniendo de manifiesto la importancia de seleccionar, explicar y valorar adecuadamente, con una perspectiva ética, lo relativo a este núcleo informativo, como sucede con otras áreas de la información periodística especializada.

Palabras clave: Información especializada, información religiosa, tensión, ética periodística, efectismo.

\begin{abstract}
:
The religious fact, so connatural to the human life, continues to be interesting in the present society and, therefore, also to the mass media. We are also coming closer to the complex and plural reality of the religious information in Spain. It asks for the specialization of professionals, and it also looks at the new routes that are offered to this type of messages in the mass media world. We detect some elements that put tension between the journalistic practice and the eclesial message. Those questions show the importance of selecting, explaining, and valuing, with an ethical perspective, all what is related to this informative nucleus, as it happens to other areas of the specialized journalistic information.
\end{abstract}

Keywords: Specialized information, religious information, tension, journalistic ethics, sensationalism.

\section{INTRODUCCIÓN}

$\mathrm{O}$ riol Domingo, responsable de la sección de religión de La Vanguardia, intervino el 11 de abril de 2007 en la Universitat Abat Oliba CEU, con una conferencia titulada La Información religiosa en primera persona: la experiencia profesional del redactor especializado en religión de La Vanguardia. Defendió Oriol que la religión es un hecho social y, por ello, noticiable e incluso suscita más interés de lo que, por impresión errónea, pueda parecer. Dos son las razones para este desinterés: el peso negativo que ha tenido en nuestro país el movimiento del nacional 
catolicismo y el bajo nivel de cultura religiosa existente debido al proceso de secularización. Además ha incidido en que el hecho religioso que es humano y social, tiene un carácter poliédrico y transversal que trata de la conciencia, por lo que se filtra en todos los terrenos de lo humano. Por esta razón nunca he disfrutado tanto como informando el hecho religioso ${ }^{1}$.

En efecto, el hecho religioso es un elemento connatural al ser humano, por lo que la religión tiene mucho que ver con la naturaleza del hombre y no puede prescindir de ninguno de sus elementos constitutivos (De Sahagún, 2000: 55). Los medios de comunicación, que se interesan por todo lo que concierne al ciudadano, incluyen en su agenda las noticias relativas a este fenómeno. En España, un país de mayoría católica, esta elevada cifra se refleja en los diferentes medios de comunicación, ya que de las informaciones religiosas que se transmiten en su generalidad abarcan temas concernientes a personajes, asuntos y celebraciones propias de la Iglesia católica. Las otras religiones aparecen en relación con ésta, por lo que localizamos dos líneas de información en este campo: ecumenismo (aproximación entre las otras confesiones cristianas) y diálogo interreligioso (con otras religiones, como el islam, el judaísmo, etc.).

La mayor parte de los fenomenólogos de la religión concluyen en definir la actitud religiosa como un encuentro personal con el absoluto. En las informaciones periodísticas hallamos más elementos sobre las mediaciones que conducen al misterio o absoluto, centro de la experiencia religiosa, que al propio núcleo del hecho religioso. Es decir, que el Papa, la posición de los obispos en determinados asuntos, algunas celebraciones, se convierten en ejes de la información religiosa y no tanto los contenidos doctrinales de la Iglesia.

Desde hace varios años, podemos ir observando que las noticias que tienen que ver con la Iglesia interesan, sin embargo no lo hacen por sí mismas, sino por su relación con otros aspectos de la vida nacional (Bosque, 1997: 181). Esta misma constatación la suscribe José María La Porte:

[...] hay un interés objetivo por la Iglesia en muchos medios, fruto del interés que tienen las audiencias a las que se dirigen. Es decir, los medios de comunicación tienen interés en la Iglesia porque ésta es noticia (La Porte, 2002: 113).

Tocamos, por tanto, uno de los ámbitos del periodismo especializado que se ha ido ordenando en torno a dos criterios: temático y geográfico. Este sistema sitúa la realidad en un contexto amplio, con unas determinadas coordenadas, relaciona y profundiza en los hechos. El objetivo es que el destinatario de la información obtenga una visión global, contextualizada y relacional. En palabras de Javier Fernández del Moral, periodismo especializado es:

[...] aquella estructura informativa que penetra y analiza la realidad a través de las distintas especialidades del saber, la coloca en un contexto amplio que ofrezca una visión global al destinatario y elabora un mensaje periodístico que acomode el código al nivel propio de cada audiencia atendiendo a sus intereses y necesidades (Fernández, 1991: 766).

\footnotetext{
1 "Oriol Domingo ha hablado de la información religiosa a los alumnos de periodismo de la UAO". Disponible en http//:www.uao.es/cream/?page=32\&post=184 [Consulta: 1 de agosto de 2007].
} 
La profesora Montserrat Quesada, tras hacer un recorrido por diferentes definiciones del periodismo especializado, ofrece su síntesis de esta materia:

[...] resulta de la aplicación minuciosa de la metodología periodística de investigación a los múltiples ámbitos temáticos que conforman la realidad social, condicionada siempre por el medio de comunicación que se utilice como canal, para dar respuesta a los intereses y necesidades de las nuevas audiencias sectoriales (Quesada, 1998: 23).

Vamos, pues, a aproximarnos en este artículo a un subcampo del periodismo especializado que es la información religiosa, ordenando y aportando información para analizar su estado en el caso español.

\section{ABUSO DE ALGUNOS INGREDIENTES DE LO NOTICIABLE}

No cabe duda de que el periodismo especializado ha de afrontar una serie de dificultades. Encontramos en ocasiones que los divulgadores no encuentran un lenguaje adecuado para dar curso a sus informaciones de una manera rigurosa por las prisas, la urgencia, precipitación e incluso por la falta de dominio de un campo específico del saber. Como sostiene Elena Blanco Castilla, el uso equívoco o inapropiado de términos es causa frecuente de protestas dirigidas a los medios por receptores o por protagonistas de la información (Blanco, 2004: 119). Pero, quizá, en el campo de lo religioso sea el exceso de determinados elementos de lo noticiable lo que desvirtúe la calidad informativa de algunos medios. Comprobémoslo a través de la revolución periodística en torno a Internet.

Aunque el desarrollo de los cibermedios ha sido vertiginoso, lo cierto es que no ha hecho más que empezar. Benedicto XVI reconoce que los avances tecnológicos en los medios han conquistado en cierta medida tiempo y espacio, haciendo la comunicación entre las personas tanto instantánea como directa, aun cuando están separadas por enormes distancias ${ }^{2}$. Los periódicos tradicionales cuentan con ediciones digitales, en las que en algunos casos tratan de reproducir tal cual los textos de la edición impresa. Pero como la red permite una producción ingente de alternativas informativas, han surgido "Los confidenciales". Con un toque editorializante, estos sitios enganchan con una visión crítica con respecto al poder establecido. Tomaremos como ejemplo un confidencial: religiondigital.com, que está vinculado a periodistadigital.com, al que una importante elite de personas recurre para estar informada de la realidad actual.

Religiondigital.com, considerado el portal más importante de información religiosa en España, renueva diariamente sus contenidos y suministra diferentes noticias sobre la Iglesia, en numerosas ocasiones extraídas de diarios de ámbito internacional, nacional, regional y de agencias, también de producción propia. Los rasgos característicos que acompañan a lo noticiable son la novedad, la oportunidad de que se conozca el acontecimiento, la excepcionalidad, los intereses editoriales del medio, etc. Así, alrededor del Papa suponen novedad las publicaciones que realiza, sus de-

\footnotetext{
2 Benedicto XVI, "Los medios: red de comunicación, comunión y cooperación". Disponible en http://www.vatican.va/holy_father/benedict_xvi/messages/communications/documents/hf_benxvi_mes_20060124_40th-world-communications-day_sp.html [Consulta: 1 de agosto de 2007].
} 
claraciones sobre temas a los que es sensible la sociedad (paz, moral sexual, solidaridad con el Tercer Mundo, diálogo con las otras religiones, etc.), lo concerniente a sus apariciones públicas, sus contactos con otros actores sociales y políticos, sus viajes y el modo de ejercer su liderazgo, así como los datos humanos sobre su biografía.

Nos detenemos en algunos asuntos que captan el interés de este portal, considerando algunos ingredientes de la noticia, conforme a la tipología de Carl Warren (cfr. Martínez, 2002: 289) y aportando casos concretos:

1. Actualidad y proximidad: Cuando se acercan beatificaciones y canonizaciones, los religiosos que suben a los altares se convierten en noticia: "Una beatificación en Bilbao" (9/05/2006), "Aita Patxi, un santo en el bando republicano" (21/06/2006), etc.

2. Conflicto: "A la Iglesia le duele quedarse sin sus privilegios" (declaraciones del jesuita Pedro Miguel Lamet en una entrevista; 24/05/2006).

3. Consecuencias: La revista Razón y fe reclama como "necesidad urgente que los partidos políticos dejen de manipular a las víctimas para que no lo sean también de los intereses políticos" (20/06/2006); "Los jesuitas españoles crearon la leyenda negra del Opus" (18/05/2006).

4. Suspense: "Secuestro de dos franciscanos en Haití" (21/07/2006); "Un informe avisa de la creciente persecución a la Iglesia en China, India, Vietnam, Rusia y Egipto" (12/07/2006).

5. Relevancia personal: Hay personas que casi siempre son capaces de producir noticias con sus actuaciones públicas: el cardenal Tarsicio Bertone, Secretario de Estado del Vaticano; el portavoz de la Santa Sede, el jesuita Federico Lombardi; las comparecencias de Juan Antonio Martínez Camino, secretario de la Conferencia Episcopal Española ("Martínez Camino arremete contra la Ley de Memoria Histórica", 31/07/2007); las afirmaciones del cardenal de Sevilla ("La Iglesia es como un cayuco"; 01/08/2007); algunas voces críticas como la del cardenal venezolano Rosalío José Castillo Lara ("Hugo Chávez es un dictador paranoico"; 01/10/2005); las declaraciones de algunos Superiores Generales, como las del salesiano Pascual Chávez ("La transmisión de la fe está rota"; 07/05/2006).

6. Rareza: "Condenan a un sacerdote en EE.UU. por matar a una monja" (11/05/2006); "El fraile del tiempo: Pello Zabala se basa en las témporas para pronosticar un verano de 'calor sano' hasta el día de Santiago" (24/06/2006); "El eremitismo, que resurge con fuerza en la era de Internet, introduce la novedad del 'ermitaño urbano' e 'intermitente'" (07/06/2006).

7. Sexo: Han sido varios los ecos de denuncias por abusos sexuales al Fundador de los Legionarios de Cristo, Marcial Maciel, así como lo relativo a la vivencia del voto de castidad: "Benedicto XVI pide 'castidad y sobriedad' a los sacerdotes y monjas" (22/05/2006). 
8. Emoción: "El misionero Chema Caballero trabaja en Sierra Leona en la reinserción de los niños soldado: 'Querían morir para escapar y sólo les mantenía en pie el recuerdo de su madre"' (05/05/2006).

9. Progreso: "Una monja española mantiene una escuela en Albania a base de donaciones" (13/07/2006); "A la escucha: Religiosos vizcaínos crean un servicio pionero para personas que necesitan ser escuchadas" (23/05/2006).

Quien navegue con asiduidad puede inferir que lo que más se destaca de la Iglesia son las tensas relaciones institucionales con el Gobierno, escándalos por abusos sexuales, anécdotas y crítica visión sobre la actuación del Papa y de algunos obispos, apostasías, etc. La polémica y lo excepcional priman excesivamente en la balanza de elección de contenidos frente a otros asuntos como el de la atención a los más necesitados o el compromiso solidario de la institución eclesial. Otros temas, que cambien el rumbo de estas perspectivas, no interesan tanto, tales como diferentes encuentros (teológicos, pastorales, convivenciales), pastoral en barrios, cárceles, hospitales, colegios, pastoral juvenil, celebraciones litúrgicas, etc. Es notoria la alergia hacia noticias que evoquen la trascendencia y el misterio de Dios. En este sentido, Fernando Donaire Martín hace memoria de los temas olvidados:

La prensa no suele mostrar la realidad de la vida de la Iglesia, ni los miles de católicos que están comprometidos en tareas sociales, ni aquellas realidades cotidianas más amables y descriptoras junto con los aspectos anteriores de una realidad tan rica y pluriforme como la Iglesia. Aunque la clientela religiosa en España es importante, es también palpable la divergencia existente entre la vida litúrgica, espiritual y apostólica, por un lado, y sus reflejos mediáticos, por otro (Donaire, 2004: 294).

\section{LA COMPLEJIDAD DE UNA REALIDAD AMPLIA, DIVERSA Y PLURAL}

Desde un boletín parroquial, diocesano o interdiocesano, pasando por revistas, publicaciones especializadas, información en prensa, radio, televisión, Internet, programas específicamente religiosos en diferentes coberturas, hasta llegar a medios de titularidad católica, nos encontramos con una oferta muy amplia que alcanza a un numerosísimo público. Es justo reconocer que desde la Iglesia cada vez hay mejores agencias de noticias:

Algunos periodistas muestran la evidencia de las muchas agencias que se han ido constituyendo los últimos años tanto en las diócesis valencianas y andaluzas como en Madrid, Aragón o en la misma Conferencia Episcopal. Se resalta mucho la agencia IVICON de la CONFER y también las agencias internacionales de información religiosa (Vidal y González-Carvajal, 2005: 193).

A esto hay que añadir que la Iglesia es una realidad plural, en la que se celebran sínodos, asambleas, encuentros y diferentes intercambios. Como en toda realidad humana, no todos adoptan la misma opinión, por lo que se da una riqueza fecunda y un contraste continuo. Un caso claro de esta complejidad nos la proporciona el buque insignia de la radio católica en España: la cadena COPE. En su libro El factor católico en la política española, Rafael Díaz-Salazar manifiesta lo siguiente: 
[...] incluso en sectores significativos de la jerarquía católica hay malestar por la polarización política de esta radio y por la cultura de la crispación que difunde. Hasta el periódico $A B C$ ha llevado a los tribunales al principal periodista de esta cadena de radio. Un buen indicador de la opinión pública de las bases católicas críticas con la COPE son los artículos de Quintín García López, sacerdote dominico, titulados: “¿Necesita Dios una radio?” y “¿Libertad de expresión o intereses en la COPE?" (en El País, 9 de noviembre de 2005 y 10 de abril de 2006)" (Díaz-Salazar, 2006: 267).

También es cierto que esta radio supone un gran servicio a la hora de la información relativa al Papa, los obispos, las diócesis, los misioneros, la labor social y caritativa de la Iglesia, etc. Para el sacerdote y experto en comunicación José María Javierre es menos claro:

[...] si conviene promover también cadenas de radio y de televisión de inspiración cristiana, porque no hay forma de mantenerlos sin abundante publicidad, y no hay publicidad sin elevados índices de audiencia, y no hay elevados índices de audiencia sin concesiones al gusto popular difícilmente conciliables con la concepción cristiana de la vida (en Vidal y González-Carvajal, 2005: 284).

Monseñor Enrique Planas, observador permanente de la Santa Sede ante el Consejo de Cultura y Comunicación de Europa, pidió medidas contra algunos comportamientos informativos de la COPE que calificó de 'suicidas' (ABC, 19/04/2007).

Refiriéndonos a la pluralidad, en el citado estudio de Díaz-Salazar se descubre una serie de organizaciones que han apoyado claramente las posiciones del magisterio y otras que han mantenido una postura antagónica:

Es interesante el análisis de algunas publicaciones periódicas dirigidas a un gran público (por ejemplo, las revistas Alba y Alfa y Omega, por un lado y 21 RS y Alandar, por otro) y de diversos sitios webs (por ejemplo, www.e-cristians.net y www.agenciaveritas.com, por un lado, y www.redescristianas.net y www.atrio.org, por otro; también merece la pena analizar www.religiondigital.com) (Díaz-Salazar, 2006: 254).

\section{PROTAGONISTAS Y CONTENIDO DE LA INFORMACIÓN RELIGIOSA}

Nos valemos de las secciones de algunos periódicos españoles (El País, El Mundo, ABC, La Razón y La Vanguardia) para detectar quiénes son los grandes protagonistas de la información religiosa y los temas que ocupan un mayor espacio en la prensa. Denominamos sección al conjunto de textos e imágenes relativos a un ámbito determinado del periódico. Política y sociedad han dado origen al resto de secciones. Las más estables son: política, economía, sociedad, deportes y opinión.

El veterano profesional Antoni Coll opina, con cierto humor, que:

[...] los diarios dedican páginas y más páginas a Política, Economía, Deportes, Espectáculos, Ofertas de contactos eróticos, etc. Y las noticias de Religión suelen meterse en el cajón de sastre de Sociedad, en la vecindad de un divorcio, de un hombre que mata a su mujer a hachazos, de los buenos efectos secundarios de la aspirina o del nacimiento de un avestruz de dos cabezas (Coll, 2006: 21). 
La Razón cuenta con una sección de religión que no suele ser diaria, y $A B C$ enmarca el asunto religioso como un bloque o subcampo de la sección "España" o "Sociedad". El País y El Mundo colocan informaciones religiosas en la sección "Gente" o "Sociedad", aunque éstas pueden localizarse en otras secciones. En La Vanguardia cuentan los domingos con la sección de religión.

En general, podemos afirmar que la información religiosa está presente en la prensa española. El hecho de que se cuente con una sección específicamente religiosa goza de sus pros y contras (Serrano, 2004: 398-399). Entre los contras destaca que la religión aparezca convertida en un gueto o que facilite a algunos lectores el saltarse la sección de religión. A favor encontramos algunas razones: fácil localización, garantía del espacio tipográfico, etc. Es evidente que el hecho de que un periódico dedique una sección o un bloque fijo a religión supone que el medio valora este tipo de contenidos informativos. En realidad, constatamos que el hecho religioso, en concreto la información sobre la Iglesia católica, no se ciñe sólo a una determinada sección sino que en ocasiones ocupa las principales secciones: internacional, nacional, sociedad, cultura. Esto puede hacernos reflexionar que la presencia de la religión no sólo en su área específica indica que el fenómeno religioso está inserto en las diferentes dimensiones de la vida humana y, por ende, lo está también en las diferentes áreas de la praxis periodística.

En un exhaustivo estudio sobre la Iglesia católica en la prensa, el profesor Diego Contreras (2004) ofrece una rica distribución de las secciones en relación con la información religiosa. Esta distribución no siempre es fija, ya que depende de los criterios del medio, de decisiones de la dirección y del consejo editorial:

1. Religión. Noticias que están ligadas al hecho religioso propiamente o vinculadas a temas propios de la institución eclesial. Las grandes fiestas del calendario litúrgico se unen en España a multitudinarias concentraciones populares en procesiones, $y$ otros actos litúrgicos y de culto. Las tradiciones españolas más arraigadas y coloristas están indisolublemente unidas a las celebraciones religiosas (Bosque, 1997: 183).

2. Internacional. Aparece la Iglesia en un contexto político diferente al país donde se edita el periódico. Aquí destacamos los viajes del Papa al extranjero. Los viajes apostólicos, fundamentalmente los de Juan Pablo II, han captado el interés de todos los medios de comunicación. Han tributado páginas literarias, donde se ha realizado un esfuerzo por captar y representar el estilo elocutivo de las personas, su modo propio de hablar: su voz, en definitiva, considerada como indicio asaz elocuente de su entera idiosincrasia (Chillón, 1999: 361). También Benedicto XVI está en el punto de mira de la opinión pública internacional y sus viajes apostólicos suscitan un interés sobresaliente, como sucedió con su estancia en Turquía tras la conocida cita extraída de un emperador bizantino de finales del siglo XIV en su discurso académico pronunciado en la Universidad de Ratisbona. En general:

[...] el episcopado es mucho más valorado cuando habla de la doctrina social de la Iglesia, y cuando hace las veces de actor internacional destacado, que cuando es portavoz de enseñanzas morales tradicionales. En estas ocasiones, aparece por lo general denostado (Donaire, 2004: 293). 
3. Nacional. Se habla de la Iglesia en relación con la política de un país. Así, como advertíamos más arriba, la posición de los obispos en torno a la unidad de España ha ocupado las páginas de la sección nacional. Suele suceder que la reunión de la Asamblea Plenaria, acto central del episcopado español, queda eclipsada por cualquier declaración que uno de los prelados haga a la prensa.

4. Cultura y sociedad. Informaciones alrededor de la cultura, el cine, la educación, la familia, el arte, el voluntariado, etc. La película El gran silencio, alrededor de la vida de los monjes cartujos, la entrada de un cardenal en la Academia de la Historia o el hallazgo del sarcófago de san Pablo son informaciones que afloran en estas secciones. En relación con el Patrimonio histórico-cultural de la Iglesia sólo es noticia la mala noticia: cuando se desploma algo (la caída de gárgolas de la Catedral de León) o la desaparición de obras de arte.

5. Local. La Iglesia asoma en noticias referentes a la ciudad o zona en la que se edita el diario. Ahí encontramos informaciones sobre la designación de cargos notables de religiosos nacidos en determinada ciudad o las declaraciones de los obispos diocesanos:

Normalmente la imagen que aparece de los curas en la prensa es de proximidad al pueblo. Ésta es la imagen de los religiosos y religiosas, de los que tampoco se olvida la labor callada y abnegada en monasterios, escuelas, hospitales y asilos. Cuando la realidad se sale de estas fronteras, encontramos a estos personajes en las páginas de sociedad, espectáculos o sucesos (Donaire, 2004: 293).

6. Deportes. Declaraciones de deportistas sobre su fe, actos de entrega de algún trofeo en alguna iglesia o llamativas noticias como la de la creación de un equipo de fútbol en El Vaticano.

7. Economía. La financiación de la Iglesia, la posición de sindicatos y empresarios en el calendario de festividades, nombramientos en Cajasur, etc. El aspecto económico presenta un gran interés, como dice Francisco Javier Bosque:

[...] los informadores llenamos la sala de prensa de la conferencia episcopal, cuando los obispos se disponen a hacer públicas las cuentas de la Iglesia, o cuando se acerca la campaña de la renta e insisten en pedir a los católicos que pongan la ya famosa crucecita en la casilla correspondiente del impreso de la declaración de hacienda (Bosque, 1997: 182).

De igual forma se pueden dar otras secciones como las especiales, sucesos, etc. En la sección de opinión o de sociedad de los periódicos se incluyen necrológicas, en las que se desarrolla la obra y personalidad de algunas relevantes personalidades de la Iglesia. En este tipo de informaciones detectamos corrientes más o menos críticas hacia los finados. Observemos el caso de la necrológica del Cardenal Javierre en El País:

Su hermano, José María Javierre, sacerdote, periodista y escritor, es autor de libros de gran éxito, el último uno voluminoso y definitivo sobre la polémica reina Isabel la Católica -Isabel la Católica. El enigma de una Reina, publicado por Ediciones Sígueme-, sobre la que el hermano del cardenal, ya casi octogenario, pudo investigar en archivos a los que sólo tienen acceso algunos privilegiados (El País, 2/02/2007). 


\section{EDUCACIÓN, MATRIMONIO, VIDA HUMANA: TEMAS DE CONTINUIDAD}

En la parcela de la educación destacan dos temas, que son ejes del debate sobre las enseñanzas de Secundaria ( $A B C, 7 / 11 / 2006)$ : la clase de religión y la asignatura de educación para la ciudadanía. La situación de los profesores de religión, las horas lectivas de la asignatura, la asignatura alternativa, el sistema evaluativo son algunos de los puntos que componen el debate sobre la enseñanza de la religión en las aulas escolares. Los medios de comunicación recogen la evolución del asunto y las diversas tendencias. La asignatura de educación para la ciudadanía ha originado un amplio debate que ha desembocado en algunos sectores al planteamiento de la objeción de conciencia de las familias contra dicha materia.

En lo que respecta al matrimonio, la celebración en Valencia en julio de 2007 del V Encuentro Mundial de las Familias con Benedicto XVI dio pie a tratar el asunto del matrimonio y a realizar varias declaraciones al respecto.

En el epígrafe de "vida humana" se tratan temas relacionados con la bioética: aborto, eutanasia, células madre, embriones, dignidad humana, etc. Estos asuntos van apareciendo continuamente en la agenda de los medios, por el interés que suscitan en congresos, con la aprobación de nuevas leyes, con las investigaciones, etc.

Estos tres temas están presentes continuamente en la prensa española. Ya lo asegura el secretario general de la Conferencia Episcopal Española, Juan Antonio Martínez Camino:

[...] las relaciones con el Gobierno socialista son correctas sólo "formalmente", porque la Iglesia católica se enfrenta a "leyes gravemente injustas", en referencia a la educación, el matrimonio o la vida humana (El País, 22/06/ 2006).

Estamos de acuerdo con Fernando Donaire en la siguiente afirmación:

[...] por encima de un planteamiento ético global, existe una información sobre aspectos fronterizos como el aborto, la eutanasia, la droga, la homosexualidad, el derecho de la mujer o la bioética. Éstos son los temas estrella que normalmente suelen aparecer mejor reflejados en las hojas de la prensa (Donaire, 2004: 293).

\section{APROVECHAMIENTO DE FUENTES EXCEPCIONALES DE REPORTEROS IN- TRÉPIDOS}

El reportero es el que practica una fuerte dosis de espíritu de iniciativa, apego a la realidad y responsabilidad. Es el que se involucra en los hechos y sus causas. Pongamos dos ejemplos en los que fácilmente podemos atisbar el compromiso de los religiosos con las más variadas situaciones de los más pobres: en los basureros del Bañado (Paraguay) y en un hogar de menores, en San Fernando (Cádiz).

María del Puerto Fernández cuenta cómo en los basureros del Bañado, en Paraguay, encontró a un anciano en un deplorable estado:

[...] un día llega a nuestra casa uno de los jóvenes estudiantes de los jesuitas y nos cuenta angustiado: El abuelo que duerme en la parada de los autobuses está 
Ileno de gusanos dentro de su piel. En ese momento sentí de nuevo la voz del Señor: Te necesito: estoy lleno de gusanos. Mi corazón se ensanchó y le dije al jesuita: Enrique, vamos ahora mismo. Nos fuimos corriendo -aquí se dice "a toda bala"- y, lo que vi, me hizo llorar. ¡Su cuerpo estaba lleno de gusanos negros! Recordé al P. Damián. Éste no era un Jesús leproso, era un Jesús agusanado.

Otro religioso, Leopoldo Antolín transmite su experiencia en un hogar de menores, en el que viven ocho chavales en situación de desamparo:

Los religiosos y educadores que estamos con ellos procuramos verlos con otros ojos, inspirados en la mirada compasiva de Jesús vemos que sus comportamientos y problemas de relación son fruto de muchos abandonos familiares, abusos de todo tipo, desestructuras, etc., que les faltaron unos brazos de madre que los mecieran de niños y un padre que de la mano les ayudara a descubrir el mundo como algo bueno y no como algo de lo que defenderse. $Y$ con esa mirada comprendemos que todas esas carencias, y todo ese rechazo que siempre han sufrido, les marca y condiciona inevitablemente de una manera muy fuerte y de por vida, haciéndoles creer además que no tienen solución. Desde esa llamada, entendemos nuestra misión.

Los dos ejemplos anteriores están tomados de revistas internas de congregaciones religiosas, en concreto de los religiosos y religiosas de los Sagrados Corazones (cfr. Cordero, 2005: 17). Dada la radicalidad a la que aspira la vida religiosa por su configuración con Cristo, podemos encontrar en los religiosos y misioneros una fuente privilegiada para aproximarnos a la realidad de los más pobres, los marginados, los afligidos y excluidos de la sociedad, en los más diferentes puntos geográficos y en situaciones difícilmente accesibles. Quien quiera descubrir en profundidad la realidad de la República Democrática del Congo o adentrarse en las colonias de leprosos en India, hallará en los misioneros una fuente veraz y próxima a la realidad, por poner un par de casos.

\section{INTERNET: POSIBILIDAD Y DESAFÍO PARA LA INFORMACIÓN RELIGIOSA}

Hay una vía para expresar libremente el carisma congregacional o las actividades diocesanas, noticias, experiencias, relatos, una manera de estar conectados con la red y con las más variadas personas que a través de ella buscan diferentes opciones: los blogs. Los weblogs, blogs o bitácoras son publicaciones individuales o grupales de la Web en las que, de manera cronológica pero sin periodicidad establecida, el autor o autores publican notas y artículos. Esos textos suelen incluir enlaces y, eventualmente, imágenes y otros contenidos multimedia. Es frecuente que brinden espacios para el comentario, donde los lectores pueden expresar libremente sus opiniones y observaciones acerca de cada una de las notas:

En razón de su naturaleza personal, en este medio interactivo los contenidos no están sometidos a ningún orden de composición (talante, estilo...); son, entonces ciertamente de carácter subjetivo, pues responden a la visión personal de sus propios autores (Alonso y Martínez, 2003: 296).

En España hay un blog que bate récords: el de las Dominicas de la Presentación de Barcelona. Un grupo de religiosas, coordinadas por Gemma Morató, Ileva más de 
tres años de funcionamiento con su página web mivocacion.com y ha conseguido 370.000 visitas y más de 6.700 correos electrónicos respondidos, en el período que va de julio de 2004 a julio de 2007. Además, estudiantes de universidades españolas se han interesado por esta página vocacional y han centrado sus trabajos en ella. En la web hay un enlace al blog de religiondigital.com. Han logrado un trabajo en equipo formado por seis religiosas dominicas, de diferentes edades, en el que cada una aporta desde sus centros de interés: Medio Oriente, imaginación, creatividad, las palabras del Papa, en busca de la verdad, etc. Cuidan de una manera especial el diseño gráfico y usan un lenguaje actual y sugerente, del que se han hecho eco diarios como El País (16/03/2006): ¿Conoces bien el mundo y la vida? Pues mejor podrás ayudar a los hombres y mujeres de este mundo. Y no serás la primera: Santa María Magdalena, sin ir más lejos, también fue una cachonda como tú. Además, este weblog tiene la particularidad de mantener un diálogo fluido con aquellos que son asiduos a sus contenidos, como es el caso de Sonia, de 28 años, que expresa que es de gran ayuda para todas aquellas que como yo buscan un sentido a su vida.

Internet se está mostrando como una herramienta crucial para la captura y circulación de informaciones cristianas y de vida religiosa, por ello algunos inciden en la necesidad de invertir en Internet y recursos informáticos, más en estos momentos de constitución inicial del medio internauta (Vidal y González-Carvajal, 2005: 194). Sin embargo, junto a una mirada positiva e ilusionante, no olvidemos que el impacto de las nuevas tecnologías plantea grandes retos, como los riesgos que vienen de la veracidad de los contenidos, por lo que habría que evaluar si lo que hemos hallado en Internet es correcto; también hemos de estar alerta de los falsos rumores que navegan tranquilamente por la red que, al ser internacional y descentralizada, pueden traspasar cualquier frontera. En su libro Médias et foi chrétienne, Guy Marchessault desarrolla una perspectiva completa de la relación entre las nuevas tecnologías, en concreto, Internet y la fe cristiana (cfr. Marchessault, 2002).

Como tantas realidades en la vida, las autopistas de la información plantean grandes oportunidades y, al mismo tiempo, diferentes peligros. Los informadores religiosos han de buscar las estrategias oportunas para que realmente las nuevas tecnologías nos ayuden, en palabras de Benedicto XVI en la citada carta apostólica, a aprovechar y ejercer las grandes oportunidades que les brindan la promoción del diálogo, el intercambio de conocimientos, la expresión de solidaridad y los vínculos de paz. De esta manera ellos se transforman en recursos incisivos y apreciados para la construcción de la civilización del amor que toda persona anhela ${ }^{3}$.

\section{UNA TELEVISIÓN PARADIGMÁTICA}

El 24 de enero de 2007, día del patrón de los periodistas, san Francisco de Sales, comenzó su andadura la televisión diocesis.tv. Se trata de la televisión por Internet de la Diócesis de Málaga, una iniciativa pionera en la comunicación de la Iglesia en España y el mundo. Esta nueva forma de hacer televisión pretende acercar el mensaje cristiano contado de forma directa y sencilla. Para ello, esta nueva plataforma cuenta con un equipo de periodistas que, diariamente, acercan a quien se conecte varios programas de corta duración. Es, sin duda, una iniciativa realizada por profesionales que engancha claramente con las posibilidades de las nuevas tecnologías para vehicular la información religiosa. Esta televisión abrirá seguramente la puerta a otras iniciativas en otros lugares, aunque hemos de recordar que la labor pionera 
en este campo la ha tenido la Madre Angélica, una monja clarisa americana, fundadora de la televisión EWTN, que se ha ido expandiendo a nivel mundial con gran éxito y que cuenta también con transmisiones de radio en 26 idiomas en 58 países, así como una creciente expansión en Internet (cfr. Gómez, 2004).

\section{CONCLUSIONES}

El interés por el hecho religioso y por la vida de la Iglesia responde a la finalidad de los medios informativos de ofrecer un servicio al ciudadano. Es, sin duda, un rasgo característico de la finalidad de los medios el proporcionar información veraz y contrastada para sus receptores. Tras ver cómo está el panorama de la agenda informativa de los medios, destacamos las siguientes reflexiones a modo de conclusiones:

La fuerza de lo excepcional. Aunque es cierto que la obra social de la Iglesia interesa a la opinión pública, no obstante, ostenta una mayor fuerza lo excepcional o cualquier tipo de escándalo en la agenda de los medios frente a la labor con los enfermos, inmigrantes o cualquier tipo de nueva pobreza. La polémica y lo excepcional priman excesivamente en la balanza de elección de contenidos frente a otros asuntos como el de la atención a los más necesitados o el compromiso solidario de la institución eclesial. Imparcialidad, independencia y autonomía son términos que no se usan con frecuencia en el periodismo actual, por lo que habría que sobrepasar el partidismo de cualquier ideología y ponderar analíticamente los juicios. Es preciso escuchar el zumbido del moscardón, es decir, activar la conciencia ética en la profesión periodística, como recuerda el profesor Martínez Albertos (cfr. 2006). Estos déficits tendría que subsanarlos la Iglesia con otros espacios como, por ejemplo, los blogs.

Necesidad de sincronización. La Iglesia ha de sincronizar su agenda con la de los medios, usar estrategias inteligentes que se adelanten a los mecanismos mediáticos. Debe aprender a utilizar adecuadamente los recursos periodísticos, renovar la manera de transmitir el mensaje de una manera atractiva y actual.

Laicidad y laicismo. La información sobre la laicidad no ha de derivar en campaña a favor del laicismo:

Para algunos agentes la cuestión del acallamiento de las religiones, especialmente de la Iglesia católica, en la vida pública se ha convertido en un núcleo central de su identidad. Hay mucho dolor en esta situación y un conflicto real en el que la reconciliación no ha sido suficiente y ello ha enquistado las posiciones. La laicidad degenera en laicismo y ello destruye la posibilidad de la laicidad (Vidal y González-Carvajal, 2006: 40).

Benedicto XVI ha advertido en varias ocasiones que el escarnio cultural sistemático de las creencias religiosas viola un derecho humano fundamental, con graves repercusiones para la convivencia pacífica $(A B C, 13 / 12 / 2006)$.

\footnotetext{
3 Benedicto XVI, "Los medios: red de comunicación, comunión y cooperación". Disponible en http://www.vatican.va/holy_father/benedict_xvi/messages/communications/documents/hf_benxvi_mes_20060124_40th-world-communications-day_sp.html [Consulta: 1 de agosto de 2007].
} 
El protagonismo de la "disidencia". Ciertos medios dan excesiva fuerza a los teólogos disidentes, a los que no están de acuerdo con el Magisterio eclesial o a noticias relativas a comunidades que se desmarcan de sus obispos. Prolongadas resonancias ha obtenido la información relativa en radio, televisión, prensa e Internet de la denominada Parroquia roja del madrileño barrio de Entrevías. Es llamativo observar el uso de las fuentes en programas de la talla de Informe Semanal, en el reportaje El cisma de Entrevías, emitido el 7 de abril de 2007. En periodismo es conveniente contrastar fuentes, investigar en diferentes lugares, en definitiva, contextualizar la información. Es oportuno incluir opiniones de teólogos que presentan una argumentación distinta a la oficial, pero para ser completos, para lograr una información de calidad, se han de ofrecer también artículos de opinión favorables a la doctrina oficial. Es cierto que determinados teólogos disidentes han alcanzado gran relevancia, sin embargo, otros navegan en la mediocridad de postulados cuyo mecanismo es ejercer de sombra crítica a lo que dictamina el Magisterio.

La tendencia al estereotipo. En titulares y en el cuerpo de la noticia se usan con frecuencia términos provenientes del ámbito jurídico-judicial e incluso bélico: "Los obispos Ilaman a cerrar filas" (El País, 13/07/2007); "Los padres católicos declaran la guerra a la educación para la ciudadanía" (La Razón, 14/09/2006); "Los obispos vascos protestan por un reportaje de El Mundo TV' (EI Mundo, 21/11/2006); "La batalla de la casilla de la renta" (El País, 4/05/2007). Da la sensación de que la Iglesia está continuamente a la contra de lo que dictamina la sociedad, que va a contracorriente del sistema de una manera impertinente y arrasadora. También encontramos determinadas metáforas que estereotipan a destacadas personalidades eclesiásticas: "Tarsicio Bertone es un puño de hierro envuelto en guante de terciopelo" ( $\mathrm{La}$ Razón, 6 de septiembre de 2006)

El efectismo para cautivar a la audiencia. Se trata de uno de los peligros de la actual cultura mediática:

Los deseos de encontrar el ángulo más atrayente, siendo muy lícitos en numerosas ocasiones, pueden forzar la realidad cuando se llevan al extremo porque llevan a una generalización o superficialidad en el tratamiento de acontecimientos con una gran carga semántica (Laporte, 2002: 118).

Pero también, puede suceder que algunos comunicadores institucionales se muevan en el reverso del efectismo con poca garra informativa y déficit de interés para las audiencias mediáticas.

Especialización en el hecho religioso. Sería pretencioso, aunque acaso no tanto, que hubiera periodistas especialistas en crónicas religiosas. Por lo menos, en las Facultades de Comunicación se podría proponer el estudio del hecho religioso en profundidad, así como las diferentes mediaciones que comprende el mismo. Las crónicas deportivas, musicales, teatrales o taurinas demandan un especialista para abordar su cometido. De igual manera, las crónicas religiosas, deberían ser realizadas por expertos que dominen el lenguaje propio del acontecimiento que refieren. En ocasiones, no emplear términos exactos conduce inevitablemente a confusiones terminológicas y a informar sin rigor. En lo relativo a la Santa Sede siempre informará con mayor exactitud y familiaridad un corresponsal permanente que un enviado es- 
pecial. Ello requerirá por parte de los medios valorar la importancia y cuidado que quieran dar al Romano Pontífice.

En algunos ambientes se da la idea de que se puede tratar el asunto religioso sin especiales conocimientos sobre el mismo. Igual que los especialistas en economía, política o ciencias no hacen comentarios gratuitos sobre sus materias, del mismo modo, para ofrecer una información clara y profunda, los profesionales han de cuidar su formación en el campo teológico y eclesial.

La diferencia entre informar y evangelizar. Es favorable, como asevera José Francisco Serrano, no confundir los planos en el pensamiento y en la actuación: una cosa es informar y otra evangelizar (Serrano, 2004: 417). Los medios están para informar y la Iglesia es objeto del interés de los medios, ya que es una institución relevante de la que se deben extraer noticias que redunden en beneficio de la sociedad. Incluso los propios informadores, cuando son católicos, reconocen tal y como cita Álex Rosal (2002: 65) lo siguiente:

[...] si hubiera sido periodista en Tierra Santa en tiempos de Jesucristo, me habría dedicado a averiguar lo que pasaba en la corte de Herodes, habría intentado que Salomé me concediera la exclusiva de sus memorias, habría descubierto lo que estaba tramando Pilatos... y me habría perdido por completo el acontecimiento más importante de todos los tiempos. A los periodistas hay que pedirles que no se queden en lo periférico de la información religiosa y a la Iglesia que tenga en cuenta la naturaleza específica de la información.

Como indica Norberto Gaitano, el papel del periodista es informar bien de las situaciones de hecho para que la opinión pública se forme un juicio correcto y no sea manipulada, particularmente por el exceso de noticias y de "razonadas sinrazones" (Gaitano, 2004: 199). Católico o no, el informador religioso ha de ser un verdadero profesional, con rigor intelectual y ético, que ha de saber transmitir con convicción y entusiasmo su producto, como invita Bruno Ballardini en su libro Jésus lave plus blanc (cfr. Ballardini, 2006).

\section{REFERENCIAS BIBLIOGRÁFICAS}

ALONSO, J.; MARTíNEZ, L. Medios interactivos: caracterización y contenidos. En DÍAZ NOCI, J.; SALAVERRÍA ALIAGA, R. (coords.) Manual de Redacción Ciberperiodística. Barcelona: Ariel, 2003, pp. 261- 305.

BALLARDINI, B. Jésus lave plus blanc. París: Éditions Liana Levi, 2003.

BENEDICTO XVI "Los medios: red de comunicación, comunión y cooperación". Disponible en http://www.vatican.va/holy father/benedict_xvi/messages/communications/document s/hf_ben-xvi_mes 20060124_40th-world-communications-day_sp.html. [Consulta: 1 de agosto de 2007].

BLANCO CASTILLA, E. Emisores de mensajes informativos. Características, tipología y comportamiento de las fuentes especializadas. En FERNÁNDEZ DEL MORAL, J. (coord.) Periodismo especializado. Barcelona: Ariel, 2004, pp. 99-121. 
BOSQUE OTERO, F. J. La información religiosa y su tratamiento periodístico: Interés, enfoque y tratamiento de las noticias religiosas. En BOROBIO, D.; RAMOS, J. (eds.) Evangelización y medios de comunicación. Salamanca: Publicaciones de la Universidad Pontificia de Salamanca, 1997, pp. 181-184.

COLL, A. Dios y los periódicos. Barcelona: Planeta, 2006.

CONTRERAS, D. La Iglesia católica en la prensa: periodismo, retórica y pragmática. Pamplona: EUNSA, 2004.

CORDERO MORALES, F. "Reporteros de comunión en la era de la Cibertorre de Babel”. Vida Religiosa, vol. 99 (2005), n 5.

CHILLÓN, A. Literatura y periodismo. Una tradición de relaciones promiscuas. Bellalterra; Castelló de la Plana; València: Server de Publicacions de la Universitat Autònoma de Barcelona, Publicacions de la Universitat Jaume I, Server de Publicacions de la Universitat de València, 1999.

DE SAHAGÚN LUCAS, J. Sagrado. En TORRES QUEIRUGA, A.(dir.) 10 palabras clave en religión. Estella: Verbo Divino, 2000, pp. 43-81.

DÍAZ-SALAZAR, R. El factor católico en la política española. Madrid: PPC, 2006.

DONAIRE MARTÍN, F. Elementos nucleares de la información religiosa. En CANTAVELLA, J.; SERRANO, J. F. (eds.) Católicos en la prensa. Madrid: Libros Libres, 2004, pp. 289-305.

FERNÁNDEZ DEL MORAL, J. Información periodística especializada. En BENITO, Á. (dir.) Diccionario de Ciencias y Técnicas de la comunicación. Madrid: Paulinas, 1991.

GAITANO, N. La formación de los periodistas católicos. En II Congreso Internacional Iglesia y Medios de Comunicación Social. Murcia: 2004, pp. 193-210.

GÓMEZ DE LA TORRE, M. La experiencia de WETN. En II Congreso Internacional Iglesia y Medios de Comunicación Social. Murcia: 2004, pp. 119-126.

LA PORTE, J. M. La lógica informativa en las noticias sobre la Iglesia. En CASTAÑEDA-COCIÑA (coord.) Iglesia y Sociedad de la Comunicación. Córdoba: Publicaciones CajaSur, 2002, pp. 113-124.

MARCHESSAULT, G. Médias et foi chrétienne. Deux univers à reconcilier. Québec: Fides, 2002.

MARTíNEZ ALBERTOS, J. L. Curso general de redacción periodística. Madrid: Thomson, 2002.

- (2006) El zumbido del moscardón. Periodismo, periódicos y textos periodísticos. Sevilla: Comunicación Social. 
QUESADA PÉREZ, M. Periodismo especializado. Madrid: Ediciones Internacionales Universitarias, 1998.

ROSAL, Á. Las diez tentaciones del periodista cristiano. En BRU, M. M. (coord.) Periodistas de primera, cristianos de verdad. Laicos en la comunicación social. Madrid: Ciudad Nueva, 2002, pp. 64-69.

SERRANO OCEJA, J. F. Información religiosa especializada. En FERNÁNDEZ DEL MORAL, J. (coord.) Periodismo especializado. Barcelona: Ariel, 2004, pp. 397-418.

VIDAL FERNÁNDEZ, F.; GONZÁLEZ-CARVAJAL, L. Medios de comunicación y religión en España. Una investigación sobre el estado de la comunicación mediática Iglesia-sociedad. Madrid: Fundación Santa María, 2005.

"Oriol Domingo ha hablado de la información religiosa a los alumnos de periodismo de la UAO". Disponible en http//:www.uao.es/cream/?page=32\&post=184 [Cconsulta: 1 de agosto de 2007].

\section{Breve semblanza del autor}

Fernando Cordero Morales es licenciado en Periodismo por la Facultad de Comunicación de la Universidad de Sevilla y Licenciado en Teología por la Facultad de Cartuja de Granada. Es colaborador desde 2005 de la asignatura "Periodismo, religión y sociedad", en la Facultad de Comunicación de Sevilla. Asimismo, ha publicado artículos sobre información religiosa en las revistas Estudios del Mensaje Periodístico, de la Universidad Complutense, en Vida Religiosa y en 21-RS.

(Recibido el 10-09-07, aceptado el 27-03-08) 